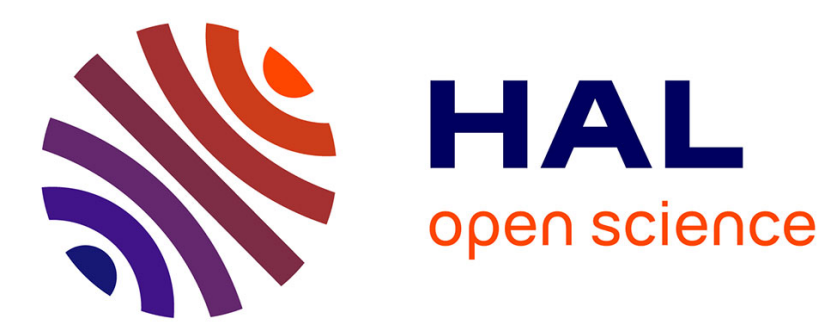

\title{
Novel Thermosensitive Polymer-Modified Liposomes as Nano-Carrier of Hydrophobic Antitumor Drugs
}

Laishun Xi, Chenglong Li, Yuandou Wang, Yanling Gong, Feng Su, S.M. Li

\section{To cite this version:}

Laishun Xi, Chenglong Li, Yuandou Wang, Yanling Gong, Feng Su, et al.. Novel Thermosensitive Polymer-Modified Liposomes as Nano-Carrier of Hydrophobic Antitumor Drugs. Journal of Pharmaceutical Sciences, 2020, 109 (8), pp.2544-2552. 10.1016/j.xphs.2020.05.006 . hal-03093011

\section{HAL Id: hal-03093011 \\ https://hal.science/hal-03093011}

Submitted on 5 Jan 2021

HAL is a multi-disciplinary open access archive for the deposit and dissemination of scientific research documents, whether they are published or not. The documents may come from teaching and research institutions in France or abroad, or from public or private research centers.
L'archive ouverte pluridisciplinaire HAL, est destinée au dépôt et à la diffusion de documents scientifiques de niveau recherche, publiés ou non, émanant des établissements d'enseignement et de recherche français ou étrangers, des laboratoires publics ou privés. 
Novel thermosensitive polymer-modified liposomes as nano-carrier of hydrophobic antitumor drugs

Laishun Xi, ${ }^{1}$ Chenglong Li, ${ }^{1}$ Yuandou Wang, ${ }^{2}$ Yanling Gong, ${ }^{1 * *}$ Feng Su, ${ }^{1,2}$, Suming $\mathrm{Li}^{3 *}$

${ }^{1}$ State Key Laboratory Base of Eco-chemical Engineering, College of Chemical Engineering, Qingdao University of Science and Technology, Qingdao 266042, China

${ }^{2}$ Institute of High Performance Polymers, Qingdao University of Science and Technology, Qingdao 266042, China

${ }^{3}$ Institut Européen des Membranes, IEM UMR 5635, Univ Montpellier, CNRS, ENSCM, Montpellier, France

*Correspondence to: Y. Gong (E-mail: hanyu_ma@126.com), and S. Li (E-mail: suming.li@umontpellier.fr)

\section{Abstract}

Thermo-sensitive polymer-modified liposomes are able to achieve site-specific delivery of drugs. In this work, thermo-sensitive polymers were synthesized by atomic transfer radical polymerization of $\mathrm{N}$-isopropyl acrylamide (NIPAAm) and N,N-dimethyl acrylamide (DMAAm) using bromoisobutyryl distearoyl phosphoethanolamine (DSPE-Br) as initiator. The resulting PNIPAAm-DSPE and P(NIPAAm-DMAAm)-DSPE polymers were characterized using proton nuclear magnetic resonance, Fourier transform infrared, and ultraviolet-visible spectroscopy. PNIPAAm-DSPE and P(NIPAAm-DMAAm)-DSPE exhibit a lower critical solution temperature of 34.0 and $46.9{ }^{\circ} \mathrm{C}$ in water, and 29.8 and $38.8{ }^{\circ} \mathrm{C}$ in phosphate buffered saline, respectively. Paclitaxel-loaded thermo-sensitive liposomes were prepared using film hydration method, followed by post-insertion of P(NIPAAm-DMAAm)-DSPE into the liposome bilayer. Drug release of traditional 
and thermosensitive liposomes was comparatively studied at 37 and $40^{\circ} \mathrm{C}$. The total release and release rate of thermosensitive liposomes at $40^{\circ} \mathrm{C}$ were much higher than those at $37^{\circ} \mathrm{C}$. And drug release is higher for thermosensitive liposomes than for traditional liposomes because insertion of thermo-sensitive polymer chains affects the system's stability. MTT assay showed that thermo-sensitive liposomes present no cytotoxicity to L929 cells at the tested concentrations, and paclitaxel-loaded liposomes have significant cytotoxicity against A549 cancer cells. Therefore, it is concluded that P(NIPAAm-DMAAm)-DSPE modified thermo-sensitive liposomes could be promising as nano-carrier of antitumor drugs.

Keywords: cancer chemotherapy; poorly water-soluble drug; polymeric drug carrier; liposome; controlled release; biocompatibility

\section{Introduction}

In the past decades, drug delivery systems such as liposomes, nanoparticles and micelles have been widely investigated as nano-carrier of hydrophobic anti-tumor drugs because of their advantages such as reduced side effects (neuropathies, neutropenia and kidney failure, etc), improved drug efficacy, and targeted drug delivery. Many drug delivery systems have reached the stage of clinical uses, including a number of liposomal systems, namely Depocyt ${ }^{\circledR}$, Doxil ${ }^{\circledR}$, Myocet ${ }^{\circledR}$, Stealth $^{\circledR}$, etc.

Traditional liposomes suffer a major limitation for clinical uses, i.e. rapid clearance from circulation by the reticuloendothelial system (RES). ${ }^{1}$ PEGylated liposomes have been developed to achieve long circulation, but the system presents poor storage stability and the release of drugs is low in human plasma. ${ }^{2}$ It has been shown that polymer-modified liposomes with introduction of long polymer chains can resist the uptake by the RES, and thus achieve long circulation in vivo. ${ }^{3}$ On the other hand, introduction of functional polymers in liposomes could be beneficial to enhance drug release..$^{4-8}$

In recent years, liposomes responsive to external stimuli such as temperature, ${ }^{4}$ 
light, ${ }^{5} \mathrm{pH},{ }^{6}$ magnetism ${ }^{7}$ and multiple stimuli, ${ }^{8}$ have attracted great interest as novel drug carrier. Temperature is the most widely studied stimulus in various stimuli-responsive systems because of its physiological significance. In fact, thermo-responsive liposomes are capable of releasing the loaded drug at a specific temperature with enhanced release rate. ${ }^{9}$ Poly(N-isopropyl acrylamide) (PNIPAAm) is the most popular thermo-sensitive polymer which exhibits a lower critical solution temperature (LCST) of $32{ }^{\circ} \mathrm{C}$ in aqueous solution due to coil-to-globule transition of polymer chains. ${ }^{10}$ It is worth mentioning that the LCST can be adjusted by copolymerization of NIPAAm and other monomers such as N,N-dimethyl acrylamide (DMAAm). ${ }^{11}$ Thermo-sensitive polymer chains could be anchored on the liposome membrane by coupling to a hydrophobic moiety that is able to dissolve in the bilayer. When the external temperature is higher than the LCST, the phospholipid membrane could be destroyed and drug released. ${ }^{12}$

Paclitaxel (PTX) is a commonly used chemotherapeutic agent with a broad spectrum of activity against cancers, especially breast cancer, ovarian cancer, non-small cell lung cancer. ${ }^{13}$ A drug carrier is required for the delivery of PTX due to its very low water solubility $(0.3 \mu \mathrm{g} / \mathrm{mL} \text { in water })^{14}$ and nonspecific cytotoxicity to normal tissues such as bone marrow, kidney and heart. ${ }^{15-17}$ The clinically used formulations of PTX are Taxol ${ }^{\circledR}$ and Abraxane ${ }^{\circledR}$. The former is composed of 50:50 Cremophor EL and dehydrated alcohol, and the latter is an injectable formulation of albumin-bound paclitaxel nanoparticles. Nevertheless, serious side effects have been reported for both systems, such as hypersensitivity reaction, nephrotoxicity, neurotoxicity and cardiotoxicity. Therefore, recent research has focused on the development of novel delivery systems of PTX, especially micelles and liposomes which can efficiently encapsulate PTX in the core or bilayer to reduce the side effects and to improve sustained drug release. ${ }^{18,19}$

Thermo-sensitive liposomes attracted much attention since local hyperthermia is increasingly considered as a safe and effective therapy in the treatment of cancers. ${ }^{4}$ It has been reported that liposomes could encapsulate paclitaxel in the phospholipid bilayer, leading to enhanced drug solubility and reduced dosage. ${ }^{20}$ Pippa et al. 
attached chain end functionalized $\mathrm{C}_{12} \mathrm{H}_{25}-\mathrm{PNIPAAm}-\mathrm{COOH}$ to 1,2-dipalmitoyl-sn-glycero-3-phosphocholine (DPPC) liposomes, and studied the temperature-dependent release of indomethacin from the liposomes. ${ }^{12}$ The in vitro release was immediate at $37{ }^{\circ} \mathrm{C}$ which is well above the LCST of PNIPAAm. Mo et al. synthesized poly(NIPAM-HPMA) copolymers by reversible addition-fragmentation chain transfer polymerization of NIPAAm and N-(2-hydroxypropyl) methacrylamide (HPMA). Thermosensitive liposomes obtained by using post-insertion method exhibited a phase transition temperature of around $42{ }^{\circ} \mathrm{C}$. With insertion of $1 \% \mathrm{p}$ (NIPAM-r-HPMA) onto the lipid bilayer, extremely quick release of encapsulated doxorubicin was achieved at $42{ }^{\circ} \mathrm{C}$. ${ }^{4}$ Wang et al. prepared PTX loaded thermo-sensitive liposomes composed of DPPC, MSPC, DSPE-PEG2000, and DSPG. ${ }^{21}$ With a phase transition temperature at $42{ }^{\circ} \mathrm{C}$ as determined by DSC, the thermo-sensitive liposomes exhibited $82 \%$ drug release at $42^{\circ} \mathrm{C}$ compared to $50 \%$ at $37^{\circ} \mathrm{C}$ after $10 \mathrm{~h}$. Only $23 \%$ drug release was observed for non thermo-sensitive liposomes. Meanwhile, PTX content in tumors was twice higher for thermo-sensitive liposomes than for non thermo-sensitive ones, probably owing to the temperature triggered release.

In our previous studies, thermo-sensitive triblock copolymers were synthesized by atomic transfer radical polymerization (ATRP) of NIPAAm and DMAAm, using $\alpha, \omega$-bromopropionyl poly(L-lactide) (Br-PLLA-Br) as macro-initiator. ${ }^{22-24}$ By tuning the ratio of NIPAAm to DMAAm, copolymers with LCST ranging from 32.3 to $49.4{ }^{\circ} \mathrm{C}$ were obtained. This work aimed to develop novel thermo-sensitive liposomes for temperature triggered release of PTX. Thermo-sensitive polymers were synthesized by ATRP of NIPAAm and DMAAm using bromoisobutyryl distearoyl phosphoethanolamine (DSPE-Br) as initiator. PTX loaded thermosensitive liposomes were then prepared by using thin film hydration and post insertion methods. Thermo-triggered release of PTX from and cytotoxicity of the liposomes were assessed to evaluate their potential as nano-carrier of PTX for the treatment of cancers. 


\section{Materials and Methods}

\section{Materials}

Hydrogenated soy phosphatidylcholine (HSPC), distearoyl phosphoethanolamine (DSPE) and cholesterol were purchased from Shanghai Advanced Vehicle Technology Co., Ltd (Shanghai, China). PTX was purchased from Sigma-Aldrich (Shanghai, China). 2-bromoisobutyryl bromide (97\%) was obtained from Alfa Aesar. Copper (I) chloride $(\mathrm{CuCl})$ and tris(2-dimethyl aminoethyl) amine $\left(\mathrm{Me}_{6}\right.$ TREN) were obtained from Tokyo Chemical Industry (TCI), Ltd (Tokyo, Japan). NIPAAm was purchased from TCI and recrystallized before used. DMAAm from TCI was purified through a basic aluminum oxide column. Triethylamine (TEA), tetrahydrofuran (THF), Ethylenediaminetetraacetic acid disodium salt (EDTA-2Na), 2-propanol, toluene, N-hexane dichloromethane, chloroform, and ethyl ether of analytical grade were obtained from Sinopharm Chemical Reagent Co., Ltd (Shanghai, China). L-929 cells (mouse fibroblasts) and A549 cells (human lung carcinoma) were purchased from ATCC (Gaithersburg, USA). Ultrapure water with a conductivity of $18.2 \mathrm{M} \Omega$ was produced using a Millipore Milli-Q water system.

\section{Synthesis of DSPE-Br Initiator}

DSPE-Br was synthesized according to the method reported by Li et al. ${ }^{25}$ Briefly, TEA $(0.8 \mathrm{mmol})$ was added into $10 \mathrm{~mL}$ of dried dichloromethane containing DSPE (0.4 mmol), and the mixture was stirred at $25{ }^{\circ} \mathrm{C}$ for $1 \mathrm{~h}$. 2-bromoisobutyryl bromide (0.4 mmol) was added dropwise into the solution which was then stirred $12 \mathrm{~h}$ at $60{ }^{\circ} \mathrm{C}$. The solution was washed with $30 \mathrm{~mL}$ ultrapure water to remove water-soluble species with separating funnel. The final product was obtained by rotary evaporation, followed by vacuum drying overnight.

\section{Synthesis of Thermosensitive Polymers}

Thermo-sensitive DSPE-P(NIPAAm-DMAAm) was synthesized using standard Schlenk technique with a [DSPE-Br]/[NIPAAm]/[DMAAm] feed ratio of 1/80/20. $89.7 \mathrm{mg}$ DSPE-Br $(0.1 \mathrm{mmol}), 905.3 \mathrm{mg}$ NIPAAm $(8.0 \mathrm{mmol})$, and $0.21 \mathrm{~mL}$ 
DMAAm $(2.0 \mathrm{mmol})$ were dissolved in $0.6 \mathrm{~mL}$ THF in a Schlenk flask, and $3 \mathrm{~mL}$ 2-propanol was then added. After three freeze-pump-thaw cycles, $26.7 \mu \mathrm{L} \mathrm{Me} 6$ TREN $(0.1 \mathrm{mmol})$ and $9.9 \mathrm{mg} \mathrm{CuCl}(0.1 \mathrm{mmol})$ were added under nitrogen atmosphere. The mixture was stirred at $30{ }^{\circ} \mathrm{C}$ for $24 \mathrm{~h}$. The crude product was dialyzed $(\mathrm{MWCO}=3500)$ in $1 \mathrm{~L}$ EDTA-2Na $(0.056 \mathrm{~g}, 0.15 \mathrm{mmol})$ solution for $48 \mathrm{~h}$ to remove residual $\mathrm{Cu}$ salts, followed by dialysis in $1 \mathrm{~L}$ water for $24 \mathrm{~h}$ to remove EDTA-2Na. Water was changed every $6 \mathrm{~h}$. The final product was obtained by lyophilization.

DSPE-PNIPAAm was prepared by using the same method with a [DSPE-Br]/[NIPAAm] feed ratio of 1/50. $89.7 \mathrm{mg}$ DSPE-Br $(0.1 \mathrm{mmol}), 565.8 \mathrm{mg}$ NIPAAm $(5.0 \mathrm{mmol}), 26.7 \mu \mathrm{L} \mathrm{Me6TREN}(0.1 \mathrm{mmol})$ and $9.9 \mathrm{mg} \mathrm{CuCl}(0.1 \mathrm{mmol})$ were used in the reaction.

\section{Preparation of Liposomes}

Liposomes were prepared by using thin film hydration method. ${ }^{26}$ Typically, 20 $\mathrm{mg}$ HSPC and $5 \mathrm{mg}$ cholesterol were dissolved in $50 \mathrm{ml}$ chloroform. The solvent was removed by rotary evaporation, followed by vacuum drying overnight to yield a thin drug-laden lipid film. The dried lipid film was hydrated with $4 \mathrm{~mL} 0.01 \mathrm{M}$ PBS (pH 7.4) at $65{ }^{\circ} \mathrm{C}$ for $2 \mathrm{~h}$. The suspension was sonicated at $80 \mathrm{~W}$ for $40 \mathrm{~min}$, and passed through $0.45 \mu \mathrm{m}$ and $0.22 \mu \mathrm{m}$ filters three times at $65{ }^{\circ} \mathrm{C}$, respectively.

The concentration of lipid in liposomes was determined by using Stewart method. ${ }^{27}$ A standard calibration curve was previously obtained with $\mathrm{R}^{2}=0.99885$ :

$$
\mathrm{A}=1.19824 \mathrm{C}-0.01096
$$

where A represents the absorbance, and $\mathrm{C}$ the concentration of lipid.

In the case of drug loaded liposomes, $1.77 \mathrm{mg}$ PTX was dissolved in the chloroform solution of HSPC and cholesterol. The same procedure was then applied. Unloaded drug was removed by centrifugation at $3000 \mathrm{rpm}(1580 \mathrm{~g})$ for $10 \mathrm{~min}$.

Polymer-modified liposomes were prepared by post-insertion method. ${ }^{28}$ The thermo-sensitive copolymer was dissolved in water at a concentration of $5 \mathrm{mg} / \mathrm{mL}$. The solution was mixed with the prepared liposomes at a DSPE/HSPC molar ratio of 
1/5. After 5 min incubation at $40{ }^{\circ} \mathrm{C}$, the mixture was cooled at $4{ }^{\circ} \mathrm{C}$ for $10 \mathrm{~min}$. The incubation/cooling cycle was repeated for $6 \mathrm{~h}$. Free polymer chains were removed by dialysis $(\mathrm{MWCO}=20000)$ for $24 \mathrm{~h}$ at $4{ }^{\circ} \mathrm{C}$ in $1 \mathrm{~L}$ of $0.01 \mathrm{M}$ PBS $(\mathrm{pH} 7.4)$ which was changed every $12 \mathrm{~h}$.

The amount of polymer attached to liposomes was determined by UV spectrophotometer (T6, General Analysis Instrument Co., Ltd., Beijing, China). ${ }^{29}$ Briefly, lyophilized polymer-modified liposomes $(3.0 \mathrm{mg})$ were dissolved in $10 \mathrm{~mL}$ methanol. The absorbance of the solution was measured at $210 \mathrm{~nm}$. The amount of copolymer was estimated from the peak area of the absorbance using a previously established calibration curve with $\mathrm{R}^{2}=0.99875$ :

$$
\mathrm{A}=11.07429 \mathrm{C}+0.01184
$$

where $\mathrm{A}$ and $\mathrm{C}$ represent absorbance and polymer concentration, respectively.

\section{Characterization}

Proton Nuclear Magnetic Resonance Spectroscopy ( ${ }^{1} H$ NMR)

${ }^{1} \mathrm{H}$ NMR was recorded from a Bruker AVANCE 500 spectrometer (Karlsruhe,

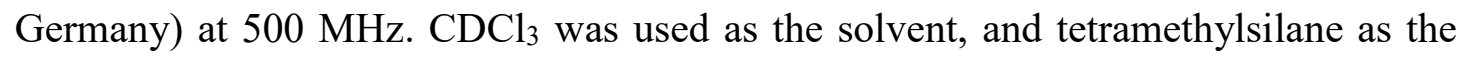
internal reference. Chemical shifts $(\delta)$ were given in ppm.

Fourier Transform Infrared Spectroscopy (FT-IR)

FT-IR was performed on a Bruker Fourier Infrared spectrometer (Kalsruhe, Germany). Sample pellets were prepared by mixing 3-5 mg of polymer with spectral grade potassium bromide, followed by compression using a press. The spectra were recorded in the range from 4000 to $400 \mathrm{~cm}^{-1}$ with a resolution of $4 \mathrm{~cm}^{-1}$. $U V$-vis Spectrophotometer (UV-vis)

The LCST of thermo-sensitive polymers was estimated from transmittance changes as a function of temperature using a Perkin Elmer Lamda 36 UV spectrophotometer (Waltham, USA) equipped with a Peltier temperature programmer

PTP-1+1. Measurements were performed at $500 \mathrm{~nm}$ with a temperature ramp of $0.1{ }^{\circ} \mathrm{C}$ $/ \mathrm{min}$. The sample concentration was $1.0 \mathrm{mg} / \mathrm{mL}$. 
The morphology of liposomes was observed on a JEM-1200EM microscope (Tokyo, Japan). Liposome solution $(5 \mu \mathrm{L})$ was dropped on a carbon-coated copper grid. Excess liquid was removed with a filter paper. The solution was negatively stained with a $1 \%$ phosphotungstic acid solution, and air-dried before observation.

\section{Dynamic Light Scattering (DLS)}

The average size and polydispersity index (PDI) of liposomes were measured using Malvern Zetasizer Nano ZS (Malvern, UK). The sample concentration was 1.0 $\mathrm{mg} / \mathrm{mL}$.

\section{Temperature-Triggered In Vitro Drug Release}

The amount of paclitaxel was measured by using high performance liquid chromatography (HPLC). A Shimadzu C18 column $(4.6 \times 250 \mathrm{~mm}$, particle size $10 \mu \mathrm{m})$ was used, and UV detector set at $227 \mathrm{~nm}$. The mobile phase was a 55:45 (v/v) mixture of water and acetonitrile. The flow rate was $1.0 \mathrm{~mL} / \mathrm{min}$. A linear calibration curve was previously obtained using 7 standard solutions in the range of $0.0025-0.08$ $\mathrm{mg} / \mathrm{mL}\left(\mathrm{R}^{2}=0.99995\right)$. The encapsulation efficiency $(\mathrm{EE})$ and drug loading content (LC) of drug loaded liposomes were determined according to the following formulas:

$$
L C=\frac{\text { weight of loaded PTX }}{\text { weight of loaded PTX and liposomes }} \times 100 \%
$$

$$
E E=\frac{\text { weight of loaded } P T X}{\text { theoretical drug loading }} \times 100 \%
$$

Drug release was performed under in vitro conditions. PTX-loaded liposome solution $(1 \mathrm{~mL})$ was added in a dialysis bag $(\mathrm{MWCO}=3500)$. The bag was placed in a tube containing $20 \mathrm{~mL}$ PBS ( $\mathrm{pH} 7.4$ ). Tween 80 at $0.1 \%$ was added to the release medium. Drug release experiments were performed in an incubator at $37{ }^{\circ} \mathrm{C}$ and $40{ }^{\circ} \mathrm{C}$, respectively. At predetermined time intervals, the release medium was removed and replaced by pre-warmed $\left(37{ }^{\circ} \mathrm{C}\right.$ or $\left.40{ }^{\circ} \mathrm{C}\right)$ fresh medium. The amount of released drug was measured by HPLC. 


\section{Cytotoxicity by MTT Assay}

L929 cells were used to assess the cytotoxicity of the polymers and liposomes. L-929 cells in logarithmic growth phase were diluted to a concentration of $1 \times 10^{4}$ cells $/ \mathrm{mL}$ in DMEM medium with $10 \%$ bovine serum, $100 \mathrm{U} / \mathrm{mL}$ penicillin, and $100 \mu \mathrm{g} / \mathrm{mL}$ streptomycinto. Cells containing suspension $(100 \mu \mathrm{L})$ was added to each well in 96-well plates. The cells were then incubated in an incubator containing 5\% $\mathrm{CO}_{2}$ at $37{ }^{\circ} \mathrm{C}$. After $24 \mathrm{~h}$, the medium was replaced with $100 \mu \mathrm{L}$ of fresh medium and blank liposomes or polymer solutions at a concentration of $0.05,0.1,0.2,0.5$ and 1.0 $\mathrm{mg} / \mathrm{mL}$, respectively. Fresh medium $(100 \mu \mathrm{L})$ was used as negative control and phenol aqueous solution $(100 \mu \mathrm{L})$ as positive control. ${ }^{30}$ After 24,48 , and $72 \mathrm{~h}, 20 \mu \mathrm{L}$ 3-(4,5-dimethylthiazol-2-yl)-2,5-diphenyltetrazolium bromide (MTT, $5.0 \mathrm{mg} / \mathrm{mL}$ in PBS) was added. After $6 \mathrm{~h}$ culture, the culture medium was discarded, and $150 \mu \mathrm{L}$ DMSO was added. After 10 min shaking, the absorbance was measured at $490 \mathrm{~nm}$ by using microplate reader (Elx800, BioTek, Winooski, USA). ${ }^{31}$ The relative growth rate is calculated according to the following equation:

$$
R G R(\%)=\frac{O D_{\text {liposome }}}{O D_{\text {negative control }}} \times 100 \%
$$

where $\mathrm{OD}_{\text {liposome }}$ and $\mathrm{OD}_{\text {negative control }}$ are the optical density (OD) values of the liposomes and the negative control, respectively.

MTT assay was also used to evaluate the in vitro cytotoxicity of PTX-loaded liposomes against A549 cancer cells in comparison with free drug. Drug-loaded liposomes were dissolved directly in culture medium, and free PTX was dissolved in $0.2 \% \mathrm{DMSO} /$ medium. Untreated cells were used as negative control. PTX concentration of both free drug and drug-loaded micelles ranged from 0.025 to 50 $\mu \mathrm{g} / \mathrm{mL}$. Experiments were carried out in pentuiplicate for each concentration. The relative activity of A549 cells was determined based on OD measurements.

\section{Results and Discussion}

Synthesis of DSPE-PNIPAAm and DSPE-P(NIPAAm-co-DMAAm) 
DSPE-PNIPAAm and DSPE-P(NIPAAm-co-DMAAm) thermo-responsive polymers were synthesized in two steps: i) reaction of the active amine group of DSPE with 2-bromoisobutyryl bromide to obtain a lipid based initiator; ii) ATRP of NIPAAm and DMAAm by bromine radical initiation with $\mathrm{Cu}^{+}$complex as bromine atomic carrier (Scheme 1).

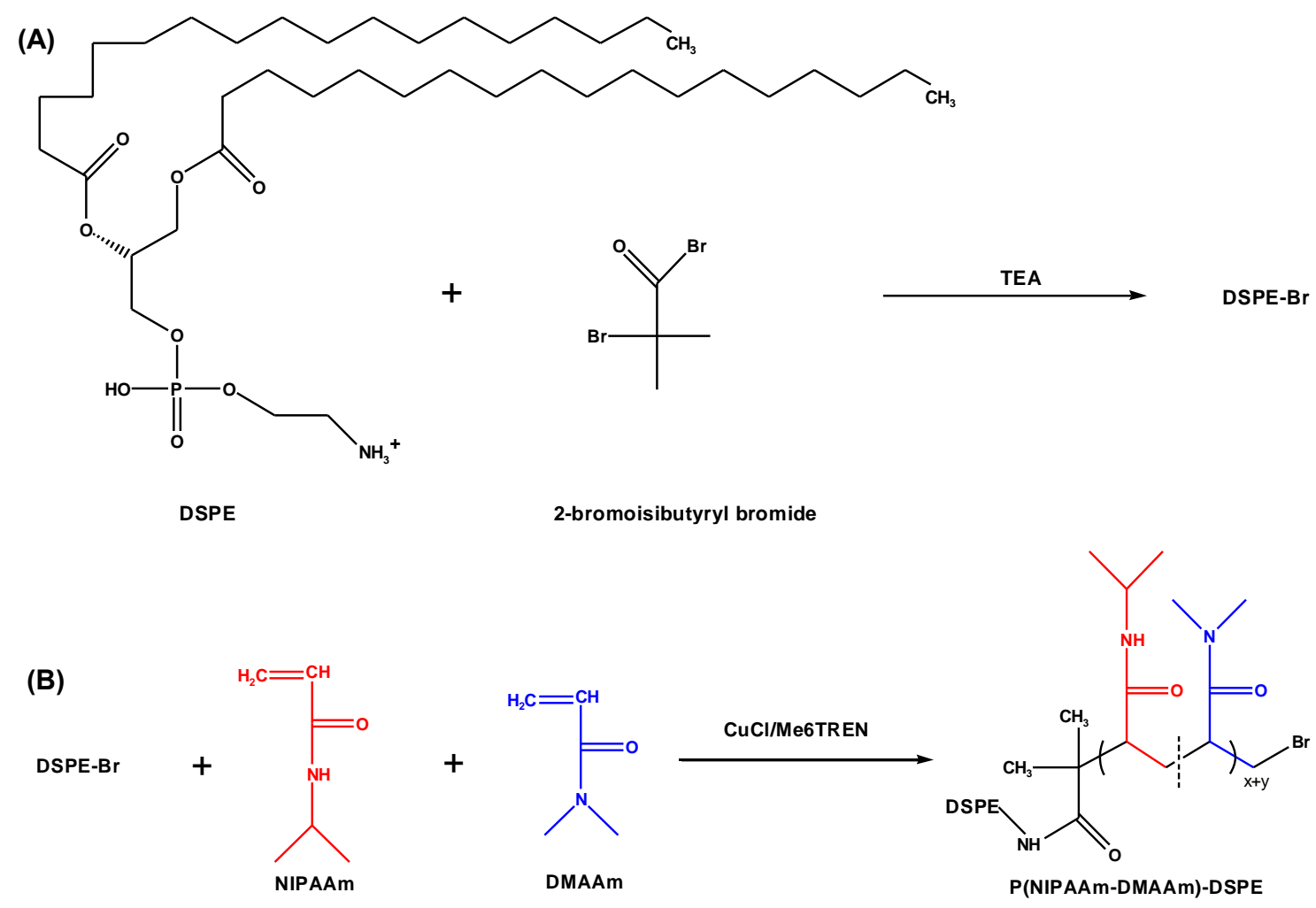

Scheme 1. (A) Synthesis of DSPE-Br initiator, (B) synthesis of DSPE-P(NIPAAm-co-DMAAm) copolymer.

The chemical composition of the polymers was determined by ${ }^{1} \mathrm{H}$ NMR. Figure 1 presents the ${ }^{1} \mathrm{H}$ NMR spectra of DSPE-Br initiator, DSPE-PNIPAAm and DSPE-P(NIPAAm-co-DMAAm). As shown in Figure 1A, the signals a at $0.8 \mathrm{ppm}$ and $\mathbf{b}$ at $1.25 \mathrm{ppm}$ are assigned to the terminal methyl group $\left(-\mathrm{CH}_{3}\right)$ of the long hydrocarbon chain of DSPE, and to the 28 methylene $\left(-\mathrm{CH}_{2}\right)$ groups, respectively. Signals $\mathbf{c}(1.6 \mathrm{ppm})$ and $\mathbf{d}(2.25 \mathrm{ppm})$ belong to the $\beta$-methylene and $\alpha$-methylene groups (- $\left.\mathrm{COCH}_{2}-\mathrm{CH}_{2}-\right)$ adjacent to the carbonyl group. Signals e (4.3 ppm), f (5.2 ppm) and $\mathbf{g}(3.98 \mathrm{ppm})$ are assigned to the methylene groups and methine group between the ester and phosphoryl groups. Signals $\mathbf{h}(4.18 \mathrm{ppm})$ and $\mathbf{i}(3.44 \mathrm{ppm})$ 
belong to the $\beta$-methylene and $\alpha$-methylene groups $\left(-\mathrm{CH}_{2}-\mathrm{CH}_{2}-\mathrm{HN}-\mathrm{CO}-\right)$ adjacent to the amide group. Finally, signal $\mathbf{j}(1.86 \mathrm{ppm})$ is attributed to the two methyl groups of 2-bromoisobutyryl group.

New signals are detected on the ${ }^{1} \mathrm{H}$ NMR spectrum of PNIPAAm-DSPE (Fig. 1B). Signals $\mathbf{n}(1.13 \mathrm{ppm})$ and $\mathbf{~ m}(4.0 \mathrm{ppm})$ are assigned to the methyl and methine protons adjacent to the amine moiety, and signals $\mathbf{k}$ and $\mathbf{l}$ in the $1.5 \sim 2.0 \mathrm{ppm}$ range to the methine and methylene protons on the PNIPAAm main chain, respectively. In the case of P(NIPAAm-DMAAm)-DSPE, more new signals are observed (Fig. 1C). Signal $\mathbf{o}$ at $2.8 \mathrm{ppm}$ belongs to the terminal methyl groups of DMAAm moieties. And signals $\mathbf{k} 1$ and $\mathbf{l}_{\mathbf{1}}$ in the $1.5 \sim 2.0 \mathrm{ppm}$ range are assigned to the methine and methylene protons on the DMAAm main chain, respectively.

The NIPAAm/DSPE and DMAAm/DSPE molar ratios were determined from the integration ratios of signals $\mathbf{a}, \mathbf{m}$, and $\mathbf{o}$, respectively. The degree of polymerization (DP) of DSPE was taken as 1. The DP of NIPAAm and DMAAm units, and the Mn of polymers were calculated according to the following equations:

$$
\begin{aligned}
& \mathrm{DP}_{\text {NIPAAm }}=\mathrm{I}_{\mathrm{m}} /\left(\mathrm{I}_{\mathrm{a}} / 6\right) \\
& \mathrm{DP}_{\text {DMAAm }}=\mathrm{I}_{\mathrm{o}} / \mathrm{I}_{\mathrm{a}} \\
& \mathrm{Mn}_{(\mathrm{NMR})}=\mathrm{Mn}_{(\mathrm{DSPE})}+\mathrm{DP}_{\mathrm{NIPAAm}} \times 113.2+\mathrm{DP}_{\text {DMAAm }} \times 99.0
\end{aligned}
$$

where $I_{a}, I_{m}$, and $I_{o}$ are the integrations of signals $\mathbf{a}, \mathbf{m}$, and $\mathbf{o}$, and 113.2 and 99.0 are the molar masses of NIPAAm and DMAAm units, respectively. 


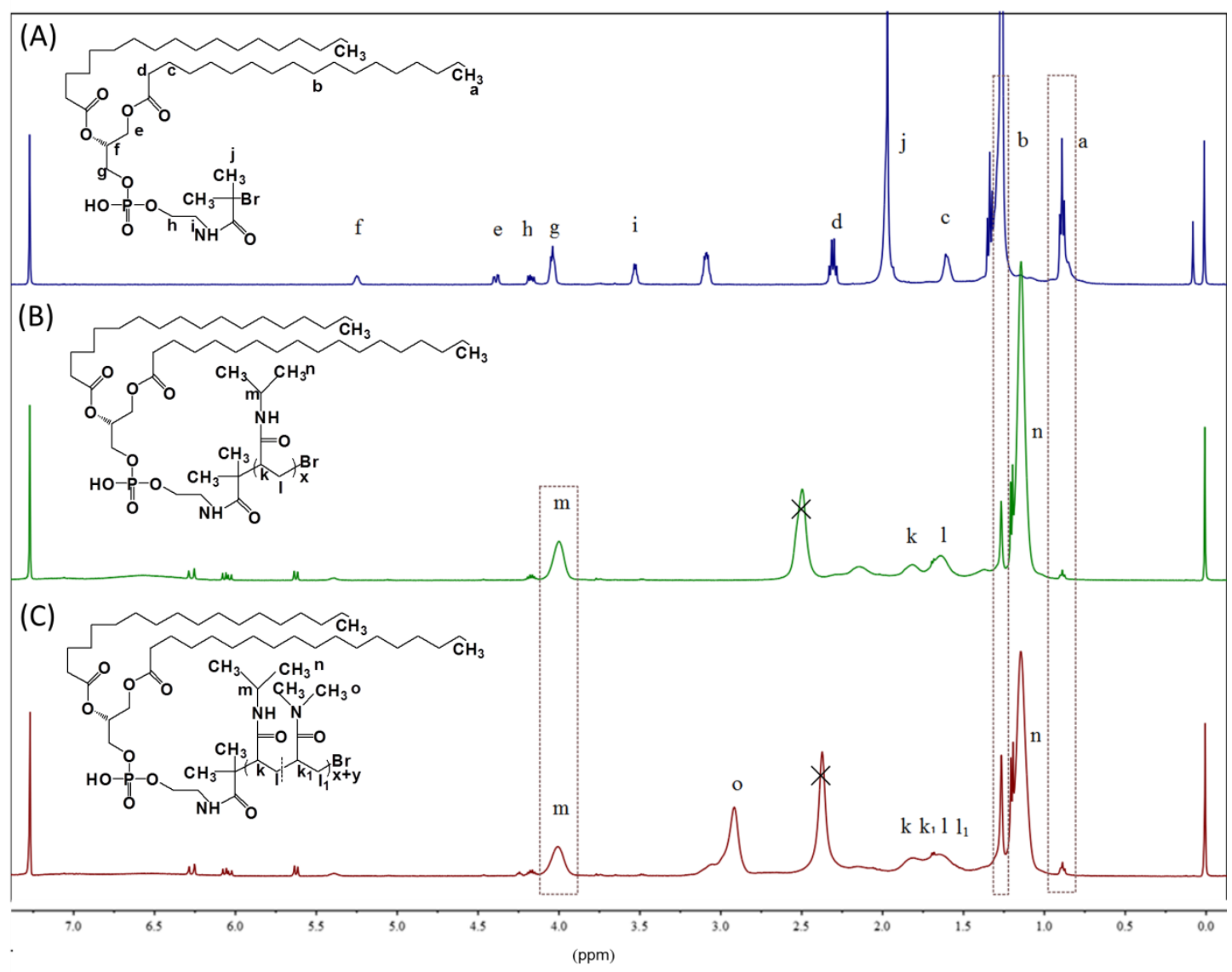

Figure 1. ${ }^{1} \mathrm{H}$ NMR Spectra of (A) DSPE-Br initiator; (B) PNIPAAm-DSPE; and (C) P(NIPAAm-DMAAm)-DSPE.

The characteristics of the two polymers are summarized in Table 1. Sample 1 designates PNIPAAm-DSPE, and Sample 2 P(NIPAAm-DMAAm)-DSPE. With a [DSPE-Br]/[NIPAAm] feed ratio of $1 / 50$, a DP NIPAAm of 27 is obtained for PNIPAAm-DSPE, corresponding to a monomer conversion of 54\%. The number average molecular weight $\left(\mathrm{M}_{\mathrm{n}}\right)$ of PNIPAAm-DSPE is 3900 as calculated from Eq. (8). In the case of P(NIPAAm-DMAAm)-DSPE copolymer, the [DSPE-Br]/[NIPAAm]/[DMAAm] feed ratio is $1 / 80 / 20$ so as to obtain a copolymer with a LCST slightly above the body temperature. ${ }^{22-24}$ The value of DP ${ }_{\text {NIPAAm }}$ and DP DMAAm was 51 and 8, corresponding to a monomer conversion was $63 \%$ and $40 \%$, respectively. The $\mathrm{M}_{n}$ of P(NIPAAm-DMAAm)-DSPE is 7500. The conversion of both monomers is relatively low compared to previous studies. ${ }^{22}$ This discrepancy could be attributed to the lower activity of DSPE-Br initiator due to steric effect. 
Table 1 Characteristics of PNIPAAm-DSPE and P(NIPAAm-DMAAm)-DSPE polymers.

\begin{tabular}{|c|c|c|c|c|c|c|}
\hline Sample & 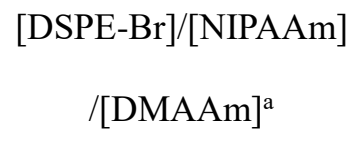 & $\begin{array}{c}\text { [DSPE-Br]/[NIPAAm] } \\
/_{[\text {DMAAm }]^{\mathrm{b}}}\end{array}$ & $\mathrm{Mn}_{(\mathrm{NMR})}$ & Conversion $^{\mathrm{c}}$ & $\begin{array}{c}\text { LCST } \\
\left(\text { in } \mathrm{H}_{2} \mathrm{O}\right)^{\mathrm{d}}\end{array}$ & $\begin{array}{c}\text { LCST } \\
\text { (in PBS) }^{\mathrm{d}}\end{array}$ \\
\hline 1 & $1 / 50 / 0$ & $1 / 27 / 0$ & 3900 & $54 \%$ & 34.0 & 29.8 \\
\hline 2 & $1 / 80 / 20$ & $1 / 51 / 8$ & 7500 & $63 \%, 40 \%$ & 46.9 & 38.8 \\
\hline
\end{tabular}

${ }^{\mathrm{a}}$ Feed ratio.

${ }^{\mathrm{b}}$ Calculated from NMR.

${ }^{\mathrm{c}}$ Monomer conversion ratio.

${ }^{\mathrm{d}}$ Determined by UV spectroscopy.

FT-IR was also employed to examine the chemical composition of the polymers as shown in Figure $1 \mathrm{~S}$ for P(NIPAm-DMAAm)-DSPE. The band at $3308 \mathrm{~cm}^{-1}$ is assigned to the imine stretching vibration, which is characteristic of the amide group. Bands at $2971 \mathrm{~cm}^{-1}$ and $2926 \mathrm{~cm}^{-1}$ belong to the symmetric and asymmetric stretching vibration of $\mathrm{C}-\mathrm{H}$ bonds, band at $1649 \mathrm{~cm}^{-1}$ to the stretching vibration of the $\mathrm{C}=\mathrm{O}$ group, band at $1544 \mathrm{~cm}^{-1}$ to the bending vibration of the imine group, bands at 1385 and $1365 \mathrm{~cm}^{-1}$ to the absorption formed by the symmetric deformation splitting of the methyl groups. The bands at $1175 \mathrm{~cm}^{-1}$ and $1130 \mathrm{~cm}^{-1}$ correspond to the vibrational absorption of the isopropyl group, which is the characteristic absorption band of isopropyl. The band at $800 \mathrm{~cm}^{-1}$ is assigned to the plane rocking vibration of methylene groups. A small band is detected at $1743 \mathrm{~cm}^{-1}$, which is assigned to the stretching vibration of ester groups of DSPE. The presence of the various bands well corroborates with the structure of P(NIPAm-DMAAm)-DSPE polymer.

\section{Lower Critical Solution Temperature}

The LCST of PNIPAAm-DSPE and P(NIPAAm-DMAAm)-DSPE was measured from the transmittance changes of polymer solutions as a function of temperature. Measurements were carried out at a concentration of $1.0 \mathrm{mg} / \mathrm{mL}$ in water and in 0.01 M PBS ( $\mathrm{pH}$ 7.4), respectively. As shown in Figure 2, the transmittance of the solutions is nearly $100 \%$ in the low temperature range, in agreement with the good 
solubility of polymers. A sharp decrease occurs at a critical temperature defined as the LCST. And the initially clear and transparent solution turns milky white because of the dehydration of PNIPAAm and P(NIPAAm-DMAAm) chains.

The LCST results are summarized in Table 1. The LCST of PNIPAAm-DSPE in water is $34.0{ }^{\circ} \mathrm{C}$, which is slightly higher the value reported in literature. ${ }^{21}$ This difference could be attributed to the presence of DSPE which enhances the polymer's hydrophilicity. The LCST of PNIPAAm-DSPE decreases to $29.8{ }^{\circ} \mathrm{C}$ in $0.01 \mathrm{M}$ PBS ( $\mathrm{pH}$ 7.4). In fact, the salts in PBS will compete with the polymer for surrounding water molecules, thus leading to dehydration of the polymer and lower LCST. This is in agreement with the Hofmeister effects of salts on macromolecule solubility. ${ }^{32,33}$ Costa et al. also observed similar phenomena in rheological studies of PNIPAAm. ${ }^{34}$

P(NIPAAm-DMAAm)-DSPE exhibits a LCST at $46.9{ }^{\circ} \mathrm{C}$ in water, and at $38.8{ }^{\circ} \mathrm{C}$ in PBS. Thus incorporation of DMAAm moieties allows to increase the LCST of the copolymers, in agreement with literature. ${ }^{21}$ Most importantly, a LCST at $38.8{ }^{\circ} \mathrm{C}$ in PBS should favor targeted delivery of drug loaded liposomes in tumor with local hyperthermia.

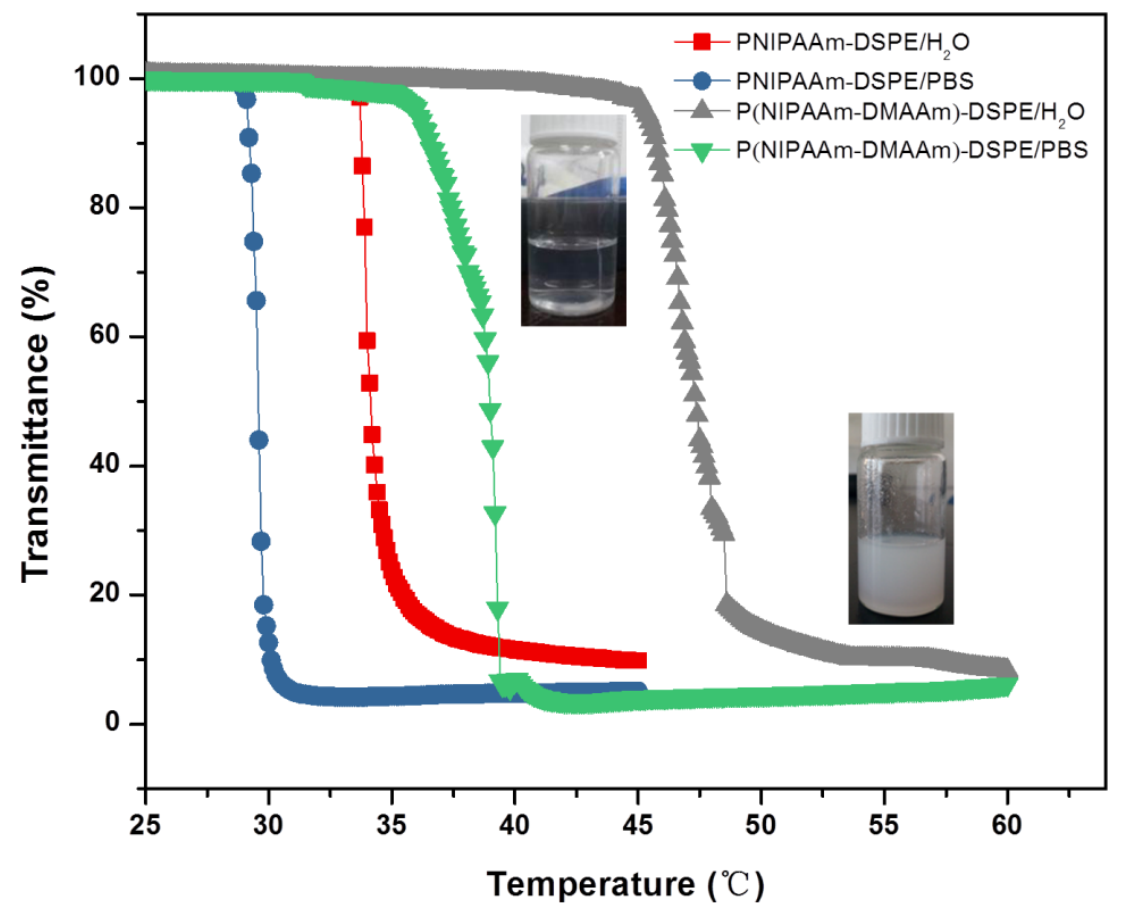

Figure 2. Transmittance changes of PNIPAAm-DSPE and P(NIPAAm-DMAAm)-DSPE solutions at $1.0 \mathrm{mg} / \mathrm{mL}$ as a function of temperature in water and in PBS. 


\section{Preparation and Characterization of Liposomes}

PTX-loaded liposomes were prepared by using film hydration method, and thermosensitive PTX-loaded liposomes were obtained via post-insertion. P(NIPAAm-DMAAm)-DSPE was used to prepare thermo-sensitive liposomes since it exhibits a LCST slightly above the body temperature. The actual HSPC phospholipid content in liposomes was $16.9 \mathrm{mg}$ as determined by the Stewarts method (Table 2), in contrast to the amount of $20 \mathrm{mg}$ initially introduced. Apparently there is some loss in the process of preparation and filtration. The thermo-sensitive polymer was inserted in liposomes at a molar ratio of P(NIPAAm-DMAAm)-DSPE/HSPC of 1:5. According to UV measurements, only $6.9 \%$ of the copolymer were successfully inserted in the liposomes. Insertion of polymer chains in liposomes could be facilitated at temperatures above the phase transition of phospholipids which is $52.7{ }^{\circ} \mathrm{C} .{ }^{35}$ Nevertheless, such high temperatures will lead to collapse of the thermosensitive copolymer chains and thus disfavor their insertion. It has been reported that 5 to $10 \%$ of DSPE modified poly(ethylene glycol) (PEG-DSPE) were inserted in liposomes. ${ }^{36}$ Kono et al. reported that insertion of $4 \%$ polymer greatly improves the temperature-sensitive drug release of polymer-modified liposomes in the presence of serum above the LCST. ${ }^{37}$ Therefore, $6.9 \%$ of the copolymer inserted in liposomes could be sufficient to favor temperature triggered drug release and long circulation.

Table 2 Physicochemical properties of PTX-loaded liposomes before and after post-insertion.

\begin{tabular}{|c|c|c|c|c|c|c|}
\hline Sample & $\begin{array}{l}\text { Diameter } \\
(\mathrm{nm})\end{array}$ & PDI & $\begin{array}{l}\text { Loading } \\
\text { content } \\
(\%)\end{array}$ & $\begin{array}{c}\text { Loading } \\
\text { efficiency }(\%)\end{array}$ & $\begin{array}{l}\text { Amount of final } \\
\text { lipid } \\
(\mathrm{mg})\end{array}$ & $\begin{array}{c}\text { Amount of } \\
\text { polymer } \\
\text { insertion (\%) }\end{array}$ \\
\hline $\begin{array}{l}\text { PTX-loaded } \\
\text { liposomes }\end{array}$ & $110.4 \pm 1.5$ & 0.152 & 7.8 & 80.5 & 16.9 & - \\
\hline $\begin{array}{c}\text { After } \\
\text { post-insertion }\end{array}$ & $111.6 \pm 0.3$ & 0.139 & 7.8 & 80.8 & 16.9 & 6.9 \\
\hline
\end{tabular}

The size, size distribution and morphology of the obtained liposomes were 
characterized by DLS and TEM measurements, as shown in Figure 3. Unmodified liposomes exhibit a diameter of $110.4 \mathrm{~nm}$ with a PDI of 0.152 at $25{ }^{\circ} \mathrm{C}$ (Fig. 2S). Uniformly distributed liposomes with spherical shape are observed (Fig. 2S). After polymer insertion, the size and shape of thermosensitive liposomes remain almost unchanged. An average particle size of $111.6 \mathrm{~nm}$ is obtained with a narrow distribution (PDI $=0.139)$ (Fig. 3A). Uniform and spherical liposomes are also observed with a size between 30 and $80 \mathrm{~nm}$ (Fig. 3B). It is noted that the diameter of liposomes obtained from TEM is smaller than that from DLS, which can be attributed to the dehydration and shrinkage of liposomes during TEM measurements. ${ }^{18}$
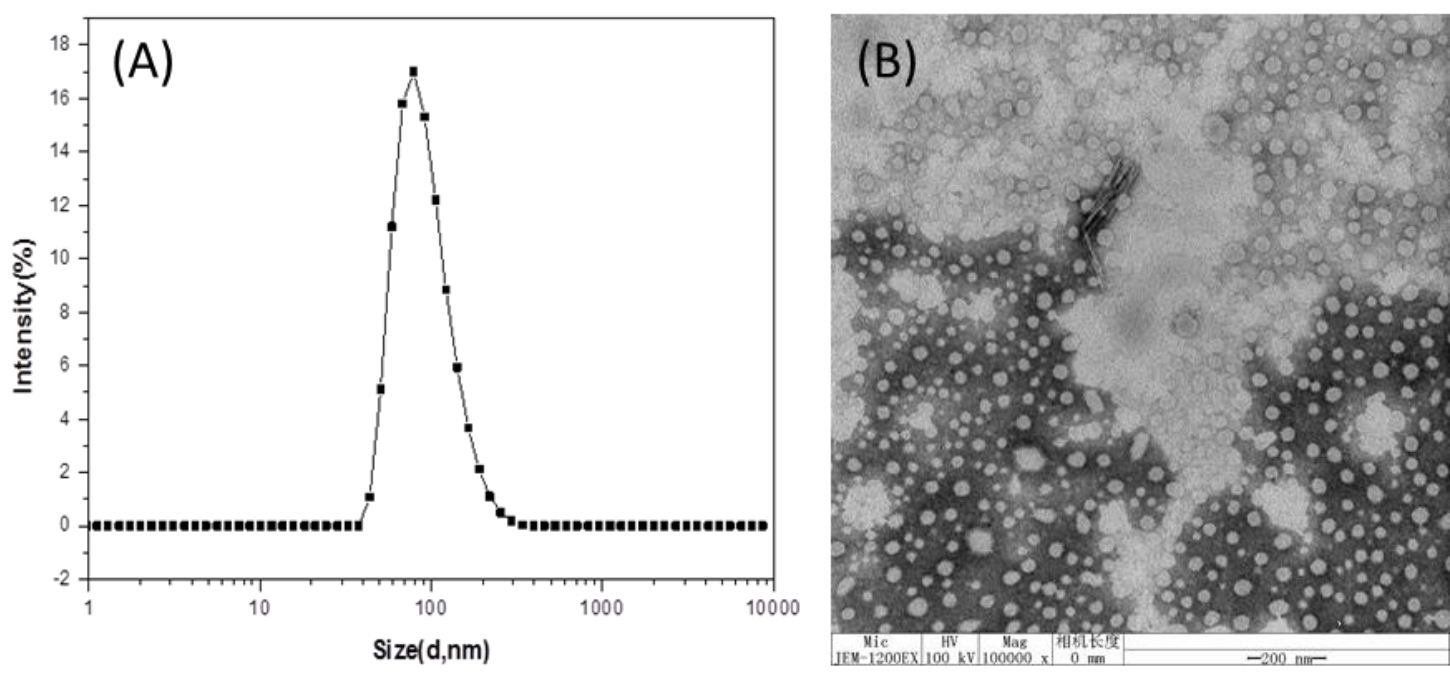

Figure. 3. (A) DLS of PTX-loaded liposomes after post-insertion; (B) TEM of PTX-loaded liposomes after post-insertion.

The drug loading efficiency and loading content are important indicators for evaluating the potential of liposomes as nano-carrier of drugs. Paclitaxel was added at a liposome/drug ratio of 11.3/1 during the preparation process, and the theoretical loading content was $8.1 \%$. The actual drug loading content was $7.8 \%$ as determined by HPLC, and the corresponding loading efficiency is $80.5 \%$. After polymer insertion, the loading efficiency and drug loading content of the thermosensitive liposomes remain almost unchanged (Table 2). Jiang et al. obtained PTX-loaded liposomes with drug loading of 5.5\%. Data showed that effective tumor suppressive effects can be achieved. ${ }^{38}$ Eloy et al. prepared liposomes loaded with PTX and rapamycin with a 
drug loading between $2 \%$ and $7 \%$, and observed cytotoxicity to cancer cells. ${ }^{39}$

\section{In Vitro Drug Release}

PTX release was comparatively studied at 37 and $40{ }^{\circ} \mathrm{C}$ for thermosensitive liposomes, and at $40^{\circ} \mathrm{C}$ for traditional liposomes, as shown in Figure 4A. Similar profiles were observed in all cases with an initial burst followed by slower release. Nevertheless, large difference of release rates was obtained. Thermosensitive liposomes exhibited the fastest release at $40{ }^{\circ} \mathrm{C}$ which is above the LCST $\left(38.8{ }^{\circ} \mathrm{C}\right)$ of P(NIPAAm-DMAAm)-DSPE. A burst of 35.5\% was detected at $24 \mathrm{~h}$, and a total release of $72.3 \%$ in 10 days. In contrast, the cumulative release from traditional liposomes was only $39.2 \%$ at $40{ }^{\circ} \mathrm{C}$ for 10 days. This finding clearly indicates that drug release was greatly enhanced for thermosensitive liposomes. On the other hand, PTX release from thermosensitive liposomes was also determined at $37{ }^{\circ} \mathrm{C}$. A total release of $51.7 \%$ was obtained in 10 days. The fact that the release rate was higher for thermosensitive liposomes $37{ }^{\circ} \mathrm{C}$ than that of traditional liposomes at $40{ }^{\circ} \mathrm{C}$ could be attributed to the instability of liposomes after insertion of thermosensitive polymer chains.
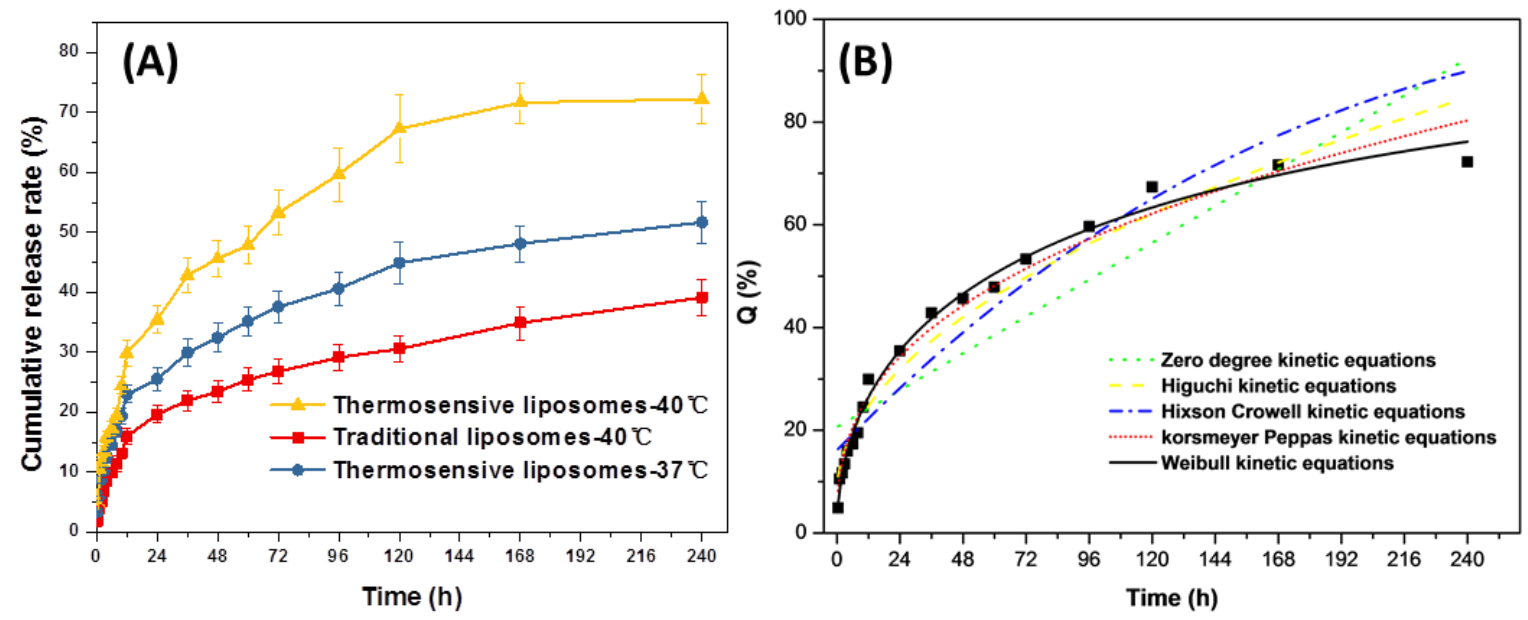

Figure 4. (A) Release profiles of PTX from liposomes at different temperatures and (B) fitting of release mechanism of temperature-sensitive liposomes at $40{ }^{\circ} \mathrm{C}$ using different models (square symbols correspond to the experimental data).

In order to investigate the release mechanism of thermosensitive liposomes, the 
release curve at $40{ }^{\circ} \mathrm{C}$ was fitted with zero-order kinetics, Higuchi, Hixson Crowell, Korsmeyer-Peppas and Weibull equations, respectively. The fitting curves of drug release are shown in Figure 4B, and the results in Table 1S. The results show that the release curve of thermosensitive liposomes at $40{ }^{\circ} \mathrm{C}$ well corroborates with the Weibull kinetic model $\left(\mathrm{R}^{2}=0.99089\right)$, and the kinetic equation is shown in the following formula :

$$
\ln \ln (1 /(1-\mathrm{Q}))=0.51464 \ln \mathrm{t}-2.45988
$$

where $\mathrm{Q}$ is the cumulative release percentage. This finding suggests a matrix type drug release for PTX loaded thermosensitive liposomes.

\section{Evaluation for Cytotoxicity of Copolymer and Blank Liposomes In Vitro}

MTT assay was used to evaluate the cytotoxicity of liposomes, using L-929 cells as standard cell line. The two thermosensitive polymers, i.e. PNIPAAm-DSPE and P(NIPAAm-DMAAm)-DSPE, traditional liposomes and P(NIPAAm-DMAAm)-DSPE inserted liposomes were co-cultured with L-929 cells. Figure 5 shows the changes in cell viability after 24, and 72 hours of co-culture. Compared to the positive control, the cell viability of PNIPAAm-DSPE, P(NIPAAm-DMAAm)-DSPE, traditional liposomes and thermosensitive liposomes group was much higher, above $80 \%$ in all cases. As the concentration of the samples increased, the relative viability of the cells slightly decreased. At the same concentration, cell viability was not affected by the culture time. According to ISO10993-5 standards, a material is cytotoxic when the relative activity of cells decreases by more than 30\%. Therefore, PNIPAAm-DSPE, P(NIPAAm-DMAAm)-DSPE, traditional liposomes, and thermosensitive liposomes are non-cytotoxic, and thus could be used as nano-carrier of drugs. 

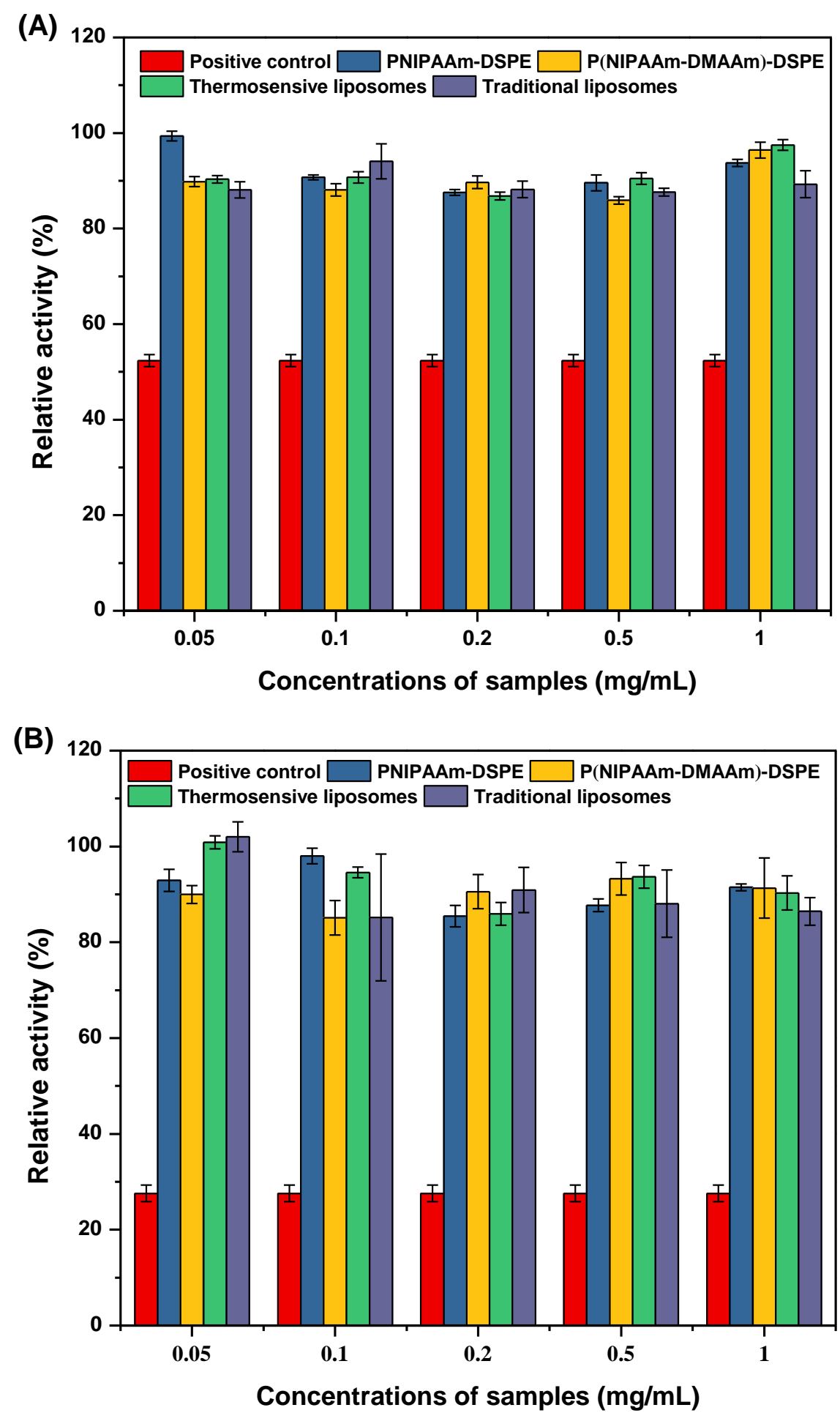

Figure 5. Relative activity of L-929 cells after (A) $24 \mathrm{~h}$, and (B) $72 \mathrm{~h}$ culture with copolymer solutions and liposomes at different concentrations as compared with the positive control. Data are presented as the mean $\pm \mathrm{SD}$.

The effect of PTX-loaded liposomes on A549 cells was evaluated by using MTT assay at $37{ }^{\circ} \mathrm{C}$, in comparison with free drug solutions. In the drug concentration range of 0.025 to $50 \mu \mathrm{g} / \mathrm{mL}$, both drug-loaded liposomes and free drug exhibited a 
certain cytotoxicity compared to the control after $72 \mathrm{~h}$ incubation, and the relative activity of A549 cells decreased with increase of the drug concentration. The free drug showed higher toxicity than the drug-loaded liposomes at the same drug concentration. This difference could be attributed to the lower drug amount available from liposomes. Therefore, it could be expected that PTX loaded liposomes could have biological effects due to prolonged drug release. Moreover, according to the drug release study (Fig. 4), higher release rate from thermo-sensitive liposomes is observed at $40{ }^{\circ} \mathrm{C}$ than at $37^{\circ} \mathrm{C}$. Thus enhanced toxicity to cancer cells could be achieved by using local hyperthermia.

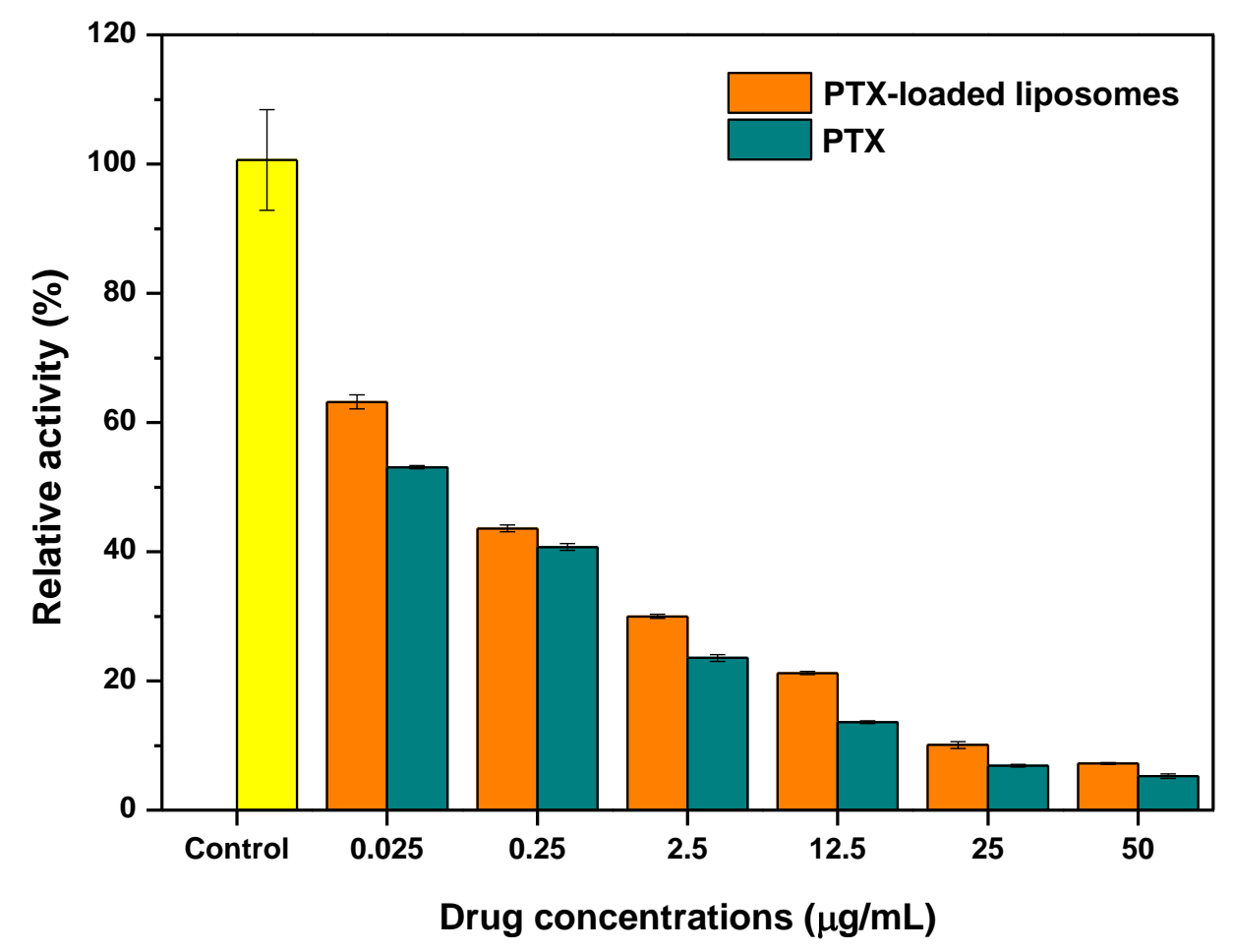

Figure 6. Relative activity of A549 cells after $72 \mathrm{~h}$ incubation with PTX-loaded liposomes and free drug at different concentrations compared to the negative control.

\section{Conclusion}

In this work, PNIPAAm-DSPE and P(NIPAAm-DMAAm)-DSPE thermosensitive polymers were successfully synthesized, and their structures was characterized by ${ }^{1} \mathrm{H}$ NMR and FT-IR. PNIPAAm-DSPE and 
P(NIPAAm-DMAAm)-DSPE exhibit a LCST of 34.0 and $46.9{ }^{\circ} \mathrm{C}$ in water, and 29.8 and $38.8{ }^{\circ} \mathrm{C}$ in PBS, respectively. P(NIPAAm-DMAAm)-DSPE was inserted into PTX loaded liposomes by a post-insertion method to obtain polymer modified thermosensitive liposomes. Drug release studies show that thermosensitive liposomes present similar drug loading and encapsulation efficiency as traditional liposomes. Nevertheless, the total release and release rate of thermosensitive liposomes at $40{ }^{\circ} \mathrm{C}$ were much higher than those at $37{ }^{\circ} \mathrm{C}$, and drug release is higher for thermosensitive liposomes than for traditional liposomes because the insertion of thermo-sensitive polymer chains affects the system's stability. Finally, MTT assay showed that thermosensitive liposomes have no cytotoxicity to L-929 cells, and paclitaxel-loaded liposomes exhibit significant cytotoxicity against A549 cancer cells. It is thus concluded that P(NIPAAm-DMAAm)-DSPE modified thermosensitive liposomes could be promising as nano-carrier of antitumor drugs.

\section{Acknowledgment}

The work was financially supported by Talent Fund of Shandong Collaborative Innovation Center of Eco-Chemical Engineering (XTCXQN20) and the 2018 Shandong Province Graduate Education Joint Training Base Construction Project (SDYJD18030).

\section{References}

1. Koudelka S, Turanek J. Liposomal paclitaxel formulations. J. Control. Release 2012;163(3):322-334.

2. Crosasso P, Ceruti M, Brusa P, Arpicco S, Dosio F, Cattel L. Preparation, characterization and properties of sterically stabilized paclitaxel-containing liposomes. J. Control. Release 2000;63(1-2):19-30.

3. Roux E, Stomp R, Giasson S, Pezolet M, Moreau P, Leroux JC. Steric stabilization of liposomes by $\mathrm{pH}$-responsive $\mathrm{N}$-isopropylacrylamide copolymer. $J$. Pharm. Sci. 2002;91(8):1795-802.

4. Alphandery E. Perspectives of breast cancer thermotherapies. $J$ Cancer 
2014;5(6):472-479.

5. Li QP, Li W, Di HX, Luo LH, Zhu CQ, Yang J, Yin XY, Yin H, Gao JQ, Du YZ, You J. A photosensitive liposome with NIR light triggered doxorubicin release as a combined photodynamic-chemo therapy system. J. Controlled Release 2018;277:114-125.

6. Lee JM, Park H, Oh KT, Lee ES. pH-Responsive hyaluronated liposomes for docetaxel delivery. Int. J. Pharm. 2018;547(1-2):377-384.

7. Choi GE, Kang MS, Kim YJ, Yoon JJ, Jeong YI. Magnetically responsive drug delivery using doxorubicin and iron oxide nanoparticle-incorporated lipocomplexes. J. Nanosci. Nanotechnol. 2019;19(2):675-679.

8. Deng YW, Ling J, Li MH. Physical stimuli-responsive liposomes and polymersomes as drug delivery vehicles based on phase transitions in the membrane. Nanoscale 2018;10(15):6781-6800.

9. Kneidl B, Peller M, Winter G, Lindner LH, Hossann M. Thermosensitive liposomal drug delivery systems: state of the art review. Int. J. Nanomed. 2014;9:4387-4398.

10. Wang J, Ayano E, Maitani Y, Kanazawa H. Tunable surface properties of temperature-responsive polymer-modified liposomes induce faster cellular uptake. Acs Omega 2017;2(1):316-325.

11. Tian HY, Tang ZH, Zhuang XL, Chen XS, Jing XB. Biodegradable synthetic polymers: Preparation, functionalization and biomedical application. Prog. Polym. Sci. 2012;37(2):237-280.

12. Pippa N, Meristoudi A, Pispas S, Demetzos C. Temperature-dependent drug release from DPPC:C12H25-PNIPAM-COOH liposomes: Control of the drug loading/release by modulation of the nanocarriers' components. Int. J. Pharm. 2015;485(1-2):374-382.

13. Bernabeu E, Cagel M, Lagomarsino E, Moretton M, Chiappetta DA. Paclitaxel: What has been done and the challenges remain ahead. Int. J. Pharm. 2017;526(1-2):474-495.

14. Lee AL, Venkataraman S, Sirat SB, Gao S, Hedrick JL, Yang YY. The use of 
cholesterol-containing biodegradable block copolymers to exploit hydrophobic interactions for the delivery of anticancer drugs. Biomaterials 2012;33(6):1921-1928.

15. Zhang FW, Zhang SY, Pollack SF, Li RC, Gonzalez AM, Fan JW, Zou J, Leininger SE, Pavia-Sanders A, Johnson R, Nelson LD, Raymond JE, Elsabahy M, Hughes DMP, Lenox MW, Gustafson TP, Wooley KL. Improving paclitaxel delivery: in vitro and in vivo characterization of PEGylated polyphosphoester-based nanocarriers. J. Am. Chem. Soc. 2015;137(5):2056-2066.

16. De Weger VA, Beijnen JH, Schellens JHM. Cellular and clinical pharmacology of the taxanes docetaxel and paclitaxel - a review. Anti-Cancer Drugs $2014 ; 25(5): 488-494$.

17. Barbuti AM, Chen ZS. Paclitaxel through the ages of anticancer therapy: exploring its role in chemoresistance and radiation therapy. Cancers 2015;7(4):2360-2371.

18. Su F, Yun P, Li CL, Li RY, Xi LS, Wang YD, Chen YS, Li SM. Novel self-assembled micelles of amphiphilic poly(2-ethyl-2-oxazoline)-poly(L-lactide) diblock copolymers for sustained drug delivery. Colloid Surface A 2019;566:120-127.

19. Nanda B, Manjappa AS, Chuttani K, Balasinor NH, Mishra AK, Murthy RSR. Acylated chitosan anchored paclitaxel loaded liposomes: Pharmacokinetic and biodistribution study in Ehrlich ascites tumor bearing mice. Int. J. Biol. Macromol. 2019;122:367-379.

20. Bhatt P, Lalani R, Vhora I, Patil S, Amrutiya J, Misra A, Mashru R. Liposomes encapsulating native and cyclodextrin enclosed paclitaxel: Enhanced loading efficiency and its pharmacokinetic evaluation. Int. J. Pharm. 2018;536(1):95-107.

21. Wang ZY, Zhang H, Yang Y, Xie XY, Yang YF, Li ZP, Li Y, Gong W, Yu FL, Yang ZB, Li MY, Mei XG. Preparation, characterization, and efficacy of thermosensitive liposomes containing paclitaxel. Drug Delivery 2016;23(4):1222-1231.

22. Hu YF, Darcos V, Monge S, Li SM. Synthesis and self-assembling of 
poly(N-isopropylacrylamide-block-poly(L-lactide)-block-poly(N-isopropylacryla mide) triblock copolymers prepared by combination of ring-opening polymerization and atom transfer radical polymerization. J Polym Sci Pol Chem 2013;51(15):3274-3283.

23. Hu YF, Darcos V, Monge S, Li SM, Zhou Y, Su F. Tunable thermo-responsive P(NIPAAm-co-DMAAm)-b-PLLA-b-P(NIPAAm-co-DMAAm) triblock copolymer micelles as drug carriers. J Mater Chem B 2014;2(18):2738-2748.

24. Hu YF, Darcos V, Monge S, Li SM, Zhou Y, Su F. Thermo-responsive release of curcumin from micelles prepared by self-assembly of amphiphilic P(NIPAAm-co-DMAAm)-b-PLLA-b-P ～(NIPAAm-co-DMAAm) triblock copolymers. Int. J. Pharm. 2014;476(1-2):31-40.

25. Li Y, Cheng Q, Jiang Q, Huang YY, Liu HM, Zhao YL, Cao WP, Ma GH, Dai FY, Liang XJ, Liang ZC, Zhang X. Enhanced endosomal/lysosomal escape by distearoyl phosphoethanolamine-polycarboxybetaine lipid for systemic delivery of siRNA. J. Controlled Release 2014;176:104-114.

26. Dua J, Rana A, Bhandari AJIJPSR. Liposome: methods of preparation and applications. Int J Pharm Stud Res 2012;3(2):14-20.

27. Stewart JC. Colorimetric determination of phospholipids with ammonium ferrothiocyanate. Anal. Biochem. 1980;104(1):10-14.

28. Hoarau D, Delmas P, David S, Roux E, Leroux JC. Novel long-circulating lipid nanocapsules. Pharm. Res. 2004;21(10):1783-1789.

29. Kono K, Nakai R, Morimoto K, Takagishi TJBEBa-B. Thermosensitive polymer-modified liposomes that release contents around physiological temperature. BBA-Biomembranes 1999;1416(1-2):239-250.

30. Li H, Niu Y. Synthesis and characterization of amphiphilic block polymer poly(ethylene glycol)-poly(propylene carbonate)-poly(ethylene glycol) for drug delivery. Mater Sci Eng C Mater Biol Appl 2018;89:160-165.

31. Belhadj Z, Ying M, Cao X, Hu XF, Zhan CY, Wei XL, Gao J, Wang XY, Yan ZQ, Lu WY. Design of Y-shaped targeting material for liposome-based multifunctional glioblastoma-targeted drug delivery. J. Controlled Release 
2017;255:132-141.

32. Zhang Y, Furyk S, Bergbreiter DE, Cremer PS. Specific ion effects on the water solubility of macromolecules: PNIPAM and the Hofmeister series. J. Am. Chem. Soc. $2005 ; 127(41): 14505-14510$.

33. Park TG, Hoffman ASJM. Sodium chloride-induced phase transition in nonionic poly (N-isopropylacrylamide) gel. Macromolecules 1993;26(19):5045-5048.

34. Costa MCM, Silva SMC, Antunes FE. Adjusting the low critical solution temperature of poly(N-isopropyl acrylamide) solutions by salts, ionic surfactants and solvents: A rheological study. J. Mol. Liq. 2015;210:113-118.

35. Uster PS, Allen TM, Daniel BE, Mendez CJ, Newman MS, Zhu GZ. Insertion of poly(ethylene glycol) derivatized phospholipid into pre-formed liposomes results in prolonged in vivo circulation time. FEBS Lett. 1996;386(2-3):243-246.

36. Jia HJ, Jia FY, Zhu BJ, Zhang WP. Preparation and characterization of glycyrrhetinic-acid loaded PEG-modified liposome based on PEG-7 glyceryl cocoate. Eur. J. Lipid Sci. Technol. 2017;119(7):1600010.

37. Kono K, Yoshino K, Takagishi T. Effect of poly(ethylene glycol) grafts on temperature-sensitivity of thermosensitive polymer-modified liposomes. $J$. Control. Release 2002;80(1-3):321-332.

38. Jiang L, Li L, He X, Yi Q, He B, Cao J, Pan W, Gu Z. Overcoming drug-resistant lung cancer by paclitaxel loaded dual-functional liposomes with mitochondria targeting and pH-response. Biomaterials 2015;52:126-139.

39. Eloy JO, Petrilli R, Topan JF, Antonio HMR, Barcellos JPA, Chesca DL, Serafini LN, Tiezzi DG, Lee RJ, Marchetti JM. Co-loaded paclitaxel/rapamycin liposomes: Development, characterization and in vitro and in vivo evaluation for breast cancer therapy. Colloids Surf. B Biointerfaces 2016;141:74-82. 